\title{
Geometrical deviation of end-of-life parts as a consequence of reshaping by single point incremental forming
}

\author{
Omer Zaheer $^{1} \cdot$ Giuseppe Ingarao $^{1} \cdot$ Antonina Pirrotta $^{1} \cdot$ Livan Fratini $^{1}$
}

Received: 18 September 2020 / Accepted: 13 April 2021 / Published online: 15 May 2021

(C) The Author(s) 2021

\begin{abstract}
Putting in place circular economy strategies is an urgent challenge to face. In this scenario, manufacturing processes play a relevant role as efficient material reuse enabler. Scientists have to make an effort either to find new process or to rethink old process to reprocess end-of-life (EoL) component to recover both material and functions. In this paper, single point incremental forming (SPIF) process is used for reshaping sheet metal EoL components. The entire process chain was replicated including both deep drawing process (to imitate the end-of-life component) as well as SPIF operations (to obtain the reshaped components). The geometrical deviation as a consequence of SPIF operations was studied; two different SPIF directions (named inwards and outwards) were analyzed. A wide experimental campaign along with statistical analyses was developed to analyze effects of some geometrical parameters on the observed geometrical deviation. The results are promising as limited distortions were observed and sound components were obtained in all the analyzed process configurations. Despite that, some research is still needed to better standardize the reshaping process and bring it closer to an industrial applicability.
\end{abstract}

Keywords Circular economy $\cdot$ Reshaping $\cdot$ SPIF $\cdot$ Geometrical deviation

\section{Introduction}

Reducing anthropogenic environmental impact is an urgent issue to deal with. Technological innovation is needed in all the economic sectors in order to replace current practices with environmentally friendly alternatives. One of the main contributors to yearly $\mathrm{CO}_{2}$ emissions is material production, accounting for about $25 \%$ of the global $\mathrm{CO}_{2}$ emissions [1]. Production processes account for about $8 \%$ of total global energy demands, which is expected to rise in the upcoming years due to decreasing ore grade [2]. Recent studies have found that the reduction of the environmental impact of material production could be achieved by the implementation of a circular economy paradigm. In other words, intense usage, product repair and upgradation, remanufacturing, component re-use, and open/closed loop recycling are some of the strategies that if implemented, keeping the existing material in the

Giuseppe Ingarao

giuseppe.ingarao@unipa.it

1 Department of Engineering, University of Palermo, Viale delle Scienze, 90128 Palermo, Italy circle, would therefore contribute towards reducing the environmental impact of raw material production [3]. The main principle focuses on turning an EoL product/component directly either into a reusable material or, better yet, into new products/components. As far as metals are concerned, recycling is still the most applied strategy as it provides environmental, technological, and economic benefits. Recycling processes can be still improved, though; solid state recycling processes have been developed for light alloy recycling [4] and have proved (for the case of aluminum alloys) to lower the environmental impact of recycling [5-7]. Nevertheless, it is, by now, urgent turning to more virtuous circular economy strategies, such us product/component reuse. Besides material itself, reuse strategies would also allow function recovery from EoL components. Function recovery would result in avoiding also the environmental impact of manufacturing processes already embodied in the EoL component/product.

In the metal reuse framework proposed by Cooper and Allwood [8], four main strategies are identified; two of them rely on superficial reconditioning and the product/component is reused either for the same type of function (in the case of relocate) or for a less demanding use (in case of cascade). The other two strategies envisage "the component(s) undergo extensive reconditioning" and these are (1) remanufacturing, 
where inspection, disassembly, re-drilling, and metallic spraying/thermal techniques are the process to be applied (typical remanufacturing applications for metals concern automotive engines and dies [9]) and (2) reform/reshape, where manufacturing approaches (additive, subtractive, mass conserving) are applied to obtain a new, more useful, geometry reprocessing the returned EoL component changing its shape. While remanufacturing has been widely analyzed by manufacturing scientists over the last years $[3,10]$, reshaping has been overlooked by the scientific community so far. In general, most of the researches are concerned with additive manufacturing application, often coupled with machining processes, either to repair or to change the EoL geometry [11, 12]. Forming processes applied specifically as reuse strategy are covered in very few scientific papers published so far. Tilwankar et al. [13] proposed to reroll steel recovered from vessels into semi-finished products (plates, bars, and rods used). Brosius et al. [14] in a review paper describe how a demounted automotive engine hood can be reshaped into a rectangular sheet metal component by sheet hydroforming process. Takano et al. [15] applied single point incremental forming (SPIF) on a flattened sheet. In fact, the reshaping they propose includes the flattening of a previously bent sheet and a subsequent incremental forming step. Abu-Farha and Khraisheh [16] proposed the application of super plastic forming for applying reshaping strategies on magnesiumbased sheet components. The aforementioned researches provide the innovative ideas of using forming process as circular economy enablers. However, these studies are preliminary and the potential of forming process in this new domain is not explored yet. It is worth mentioning that there is a lack of process mechanics analyses; for the proposed processes neither process windows nor process parameter influence has been analyzed so far. The authors of the present paper have recently proved a novel approach to reshape sheet metal based EoL components [17]. Specifically, SPIF was used to change the shape of deep-drawn (DD) square box part, the technical feasibility in terms of formability, stains, and thickness distribution was proved for the aluminum-based component reshaping. The authors have also proved the energy efficiency of such an approach [18]. They have developed a comparative analysis with respect conventional (re-melting based) path proving the environmental impact reduction provided by reshaping. It is worth remarking that returned components are normally characterized by high heterogeneity as there are localized thinning areas (caused by the original forming processes) while large part of the component underwent limited deformation. The thinned zones might be characterized by a limited residual formability while, in the less deformed zones, it is still possible to take advantage of almost the entire original formability. The selection of SPIF process was intended to overcome the aforementioned issues efficiently. In fact, SPIF is a flexible process, characterized by a local forming action. Its local action along with its enhanced formability has been widely proved [19]. Such advantages are the result of the unique process mechanics of SPIF $[20,21]$.

In this paper a new aspect of the reshaping process by SPIF is evaluated, the main aim is to analyze and quantify the geometrical deviation caused by SPIF process (in the zones not worked on by with SPIF process). In fact, although SPIF process is characterized by low forming loads [22], some distortions actions on the EoL part are still applied and geometrical deviation may occur. This paper, therefore, aims on analyzing such aspects and to provide guidelines to bring this approach closer to an industrial applicability.

\section{The proposed reshaping approach}

The main aim of this research was to reshape previously deformed metal components in order to impart a different use so as to avoid material wastage. The proposed approach is relying on the possibility of safely disassembling a large sheet metal component from EoL products, such as automobile body, washing machines, etc. and directly giving them an additional form through SPIF process. Since the research was driven by the intent of reshaping, a virgin blank sheet was given an initial deformation in the form of a square cup through deep drawing process, a commonly utilized stamping process. Doing so, an imitation of an EoL product was created, ready to be reshaped for another use of the same component. In order to cover a larger portion of production scenarios, two different SPIF

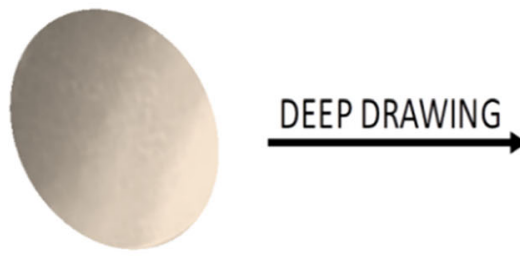

Metal Blank

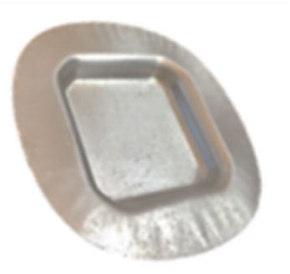

Square Cup

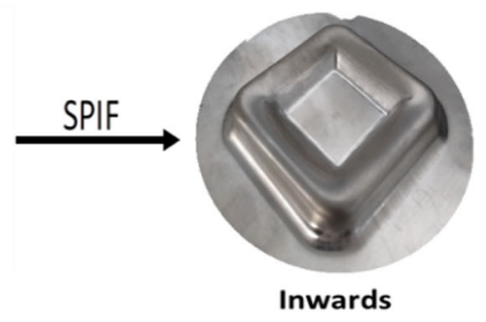

Reshaped Components

Fig. 1 Approach utilized for research realization 
Fig. 2 Geometrical parameters: a end-of-life component, b new/ reshaped component

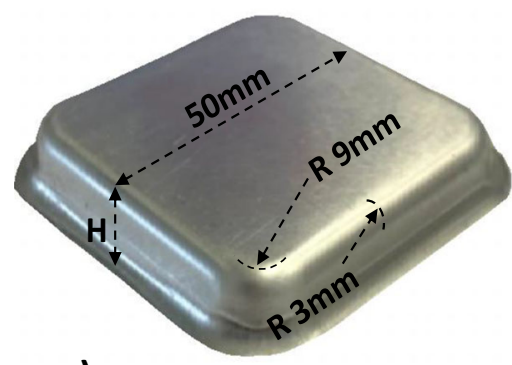

a)

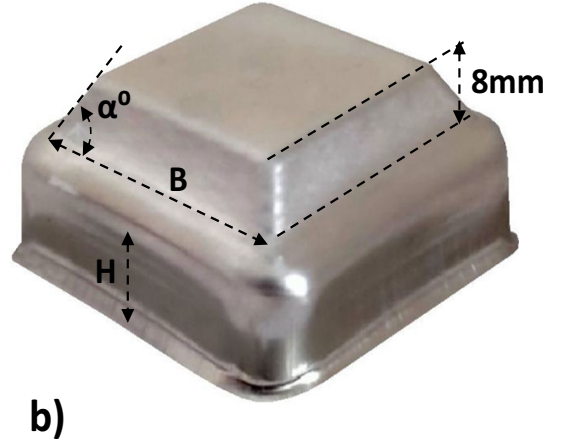

approaches were implemented. That is, SPIF process was carried out on the base of the square cup imparting an additional truncated pyramid shape from both inwards as well as outwards directions as illustrated in Fig. 1. As it can be seen, the square cup carried out by deep drawing process is here considered the EoL component to be reshaped. The reshaped component was then obtained by applying SPIF process. This choice was driven by the will to simulate the entire process chain.

\section{Materials and methods}

The experiments were performed on an AA5754 aluminum alloy, $0.5 \mathrm{~mm}$ thick. The deep drawing process was characterized by a filet radius of $3 \mathrm{~mm}$ and a base of $50 \mathrm{~mm}$, as depicted in Fig. 2. In order to analyze the effect of geometrical parameters on the accuracy of the reshaped component, some of them had been varied, in particular, the height of the deepdrawn part $(\mathrm{H})$, the SPIF angle $(\alpha)$, and the SPIF base (B).
Geometrical parameters selected for the deep drawing as well as SPIF process for developing the analysis are illustrated in Fig. 2, along with the annotations. Two levels for each parameter have been selected, and a full factorial design was performed for each SPIF direction; thus, a total of 16 configurations were analyzed, as reported in Table 1. Considering the selected levels for each parameter, the higher numerical value is being selected very close to the part property limits. In fact, in case of the angle selected, which according to the existing literature, was found to be $65^{\circ}$ [17] and the maximum value selected in this case study was $60^{\circ}$, whereas the lower value was selected as $45^{\circ}$, significant for the scope of the paper.

Similarly, for the SPIF base the values were selected as close as possible to the square cup corners as well as decently far from the corners. As far as deep drawing height $(\mathrm{H})$ is concerned, the higher value was selected as a limit, in fact a value much higher than that selected caused fracture because of the process limit (too high local deep drawing ratio). Each process configuration was performed thrice for result

Table 1 Geometrical parameter notations and combinations for each experiment

\begin{tabular}{lllll}
\hline Case study & Experiment ID & Deep drawing height $(\mathrm{H}, \mathrm{mm})$ & SPIF pyramid base $(\mathrm{B}, \mathrm{mm})$ & SPIF pyramid angle $\left(\alpha^{\circ}\right)$ \\
\hline SPIF in outwards direction & 1 & 8 & 34 & $30^{\circ}$ \\
& 2 & 8 & 34 & $60^{\circ}$ \\
& 3 & 8 & 41 & $30^{\circ}$ \\
& 4 & 8 & 41 & $60^{\circ}$ \\
& 5 & 16 & 34 & $30^{\circ}$ \\
SPIF in inwards direction & 6 & 16 & 34 & $60^{\circ}$ \\
& 7 & 16 & 41 & $30^{\circ}$ \\
& 8 & 16 & 41 & $60^{\circ}$ \\
& 10 & 8 & 34 & $30^{\circ}$ \\
& 11 & 8 & 34 & $60^{\circ}$ \\
& 12 & 8 & 41 & $30^{\circ}$ \\
& 13 & 8 & 41 & $60^{\circ}$ \\
& 14 & 16 & 34 & $30^{\circ}$ \\
& 16 & 16 & 34 & $60^{\circ}$ \\
\end{tabular}




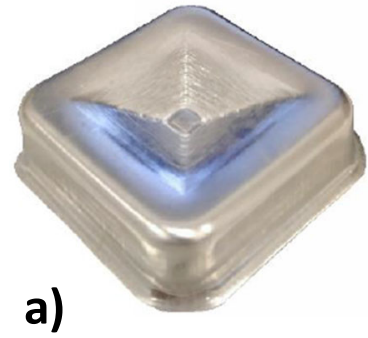

b)
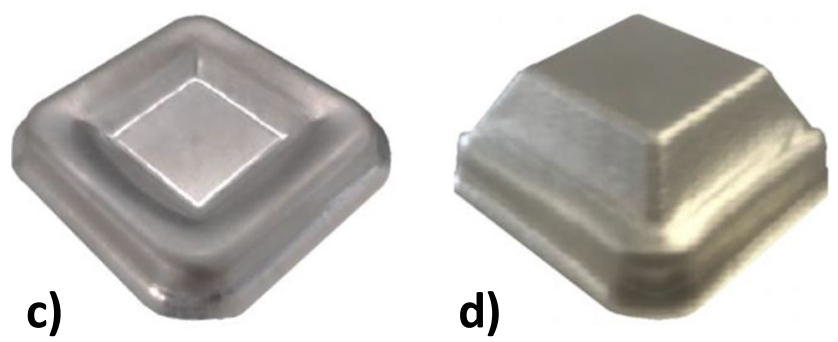

Fig. 3 Obtained parts with experiment ID: a 13, b 3, c 2, d 16

consistency, since the difference in the obtained results was smaller than two orders of magnitude with respect to the average value, only the average value has been reported in Table 1.

Although the SPIF process causes severe thinning in the cone walls [17], sound samples were obtained for all the experiments. In Fig. 3, the reshaped samples of four different parameter combinations are reported (Fig. 4).

In this research the clamping system for performing SPIF was set up on a 4 axes CNC milling machine, a tool with a high-speed steel based $4 \mathrm{~mm}$ diameter was used. A helical tool path with a $0.2 \mathrm{~mm}$ descent was applied for each revolution of the tool.
The aim of the paper is to evaluate the geometrical deviation caused by SPIF process, in this respect the shape of the reshaped component had to be compared with that of the EoL part. In order to do so, the outer surface of the component was acquired both after deep drawing and after SPIF, utilizing a photo acquisition system, "Steinbichler COMET" Laser Scanner. The acquired geometries were then analyzed through GeoMagic Control X software, which through the function of auto alignment between EoL and reshaped part geometries yielded the maximum deviation and the root mean squared error between the non-worked zones, i.e., the lateral walls of the square cup. The observations and results are detailed in "Section 4."

\section{Results analysis and discussion}

\subsection{SPIF operation in outward direction}

The first case study involved the addition of a truncated pyramid by SPIF at the center of the base of the deep-drawn parts in the outwards direction. All the results have been reported in Table 2, where the maximum deviation and the root mean squared error have been indicated.

As seen from the results, the maximum deviation was observed in experiment ID 7, the analysis result of which is illustrated in Fig. 5. In Fig. 5, the profiles of a selected cutting plane are compared. As it can be seen, the forming load required by the SPIF operation draws in the lateral walls inwards. To explore the influence of different parameter

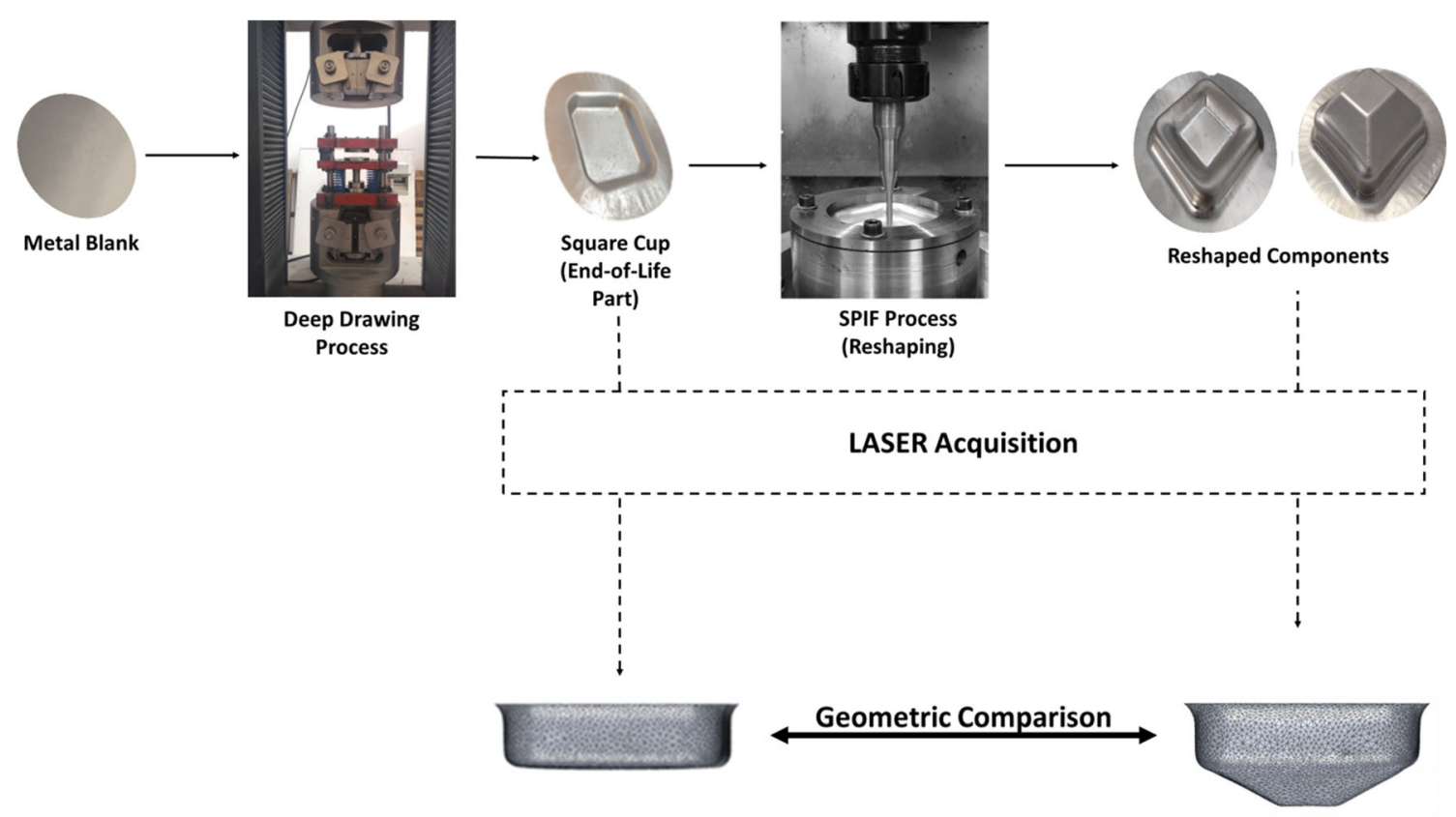

Fig. 4 Experimental workflow 
Table 2 Maximum deviations and RMS values recorded and from analysis in outwards direction

\begin{tabular}{llllll}
\hline Experiment ID & $\begin{array}{l}\text { Deep drawing height } \\
(\mathrm{H}, \mathrm{mm})\end{array}$ & $\begin{array}{l}\text { SPIF pyramid base } \\
(\mathrm{B}, \mathrm{mm})\end{array}$ & SPIF pyramid angle $\left(\alpha^{\circ}\right)$ & $\begin{array}{l}\text { Maximum deviation } \\
(\mathrm{mm})\end{array}$ & $\begin{array}{l}\text { Root mean squared } \\
(\mathrm{RMS}) \text { value }\end{array}$ \\
\hline 1 & 8 & 34 & $30^{\circ}$ & 0.178 & 0.071 \\
2 & 8 & 34 & $60^{\circ}$ & 0.308 & 0.129 \\
3 & 8 & 41 & $30^{\circ}$ & 0.322 & 0.132 \\
4 & 8 & 41 & $60^{\circ}$ & 0.116 & 0.061 \\
5 & 16 & 34 & $30^{\circ}$ & 0.333 & 0.139 \\
6 & 16 & 34 & $60^{\circ}$ & 0.319 & 0.131 \\
7 & 16 & 41 & $30^{\circ}$ & 0.681 & 0.255 \\
8 & 16 & 41 & $60^{\circ}$ & 0.541 & 0.197 \\
\hline
\end{tabular}

influences, a Pareto analysis was conducted. A Pareto analysis is a statistical technique used in order to understand the relationship between parameters and effects indicating the most influential parameter producing the most significant overall effect. This analysis helps in root cause investigations by assisting the identification of the principal influencers of the obtained results [23]. The chart indicates a reference line to highlight the statistically significant parameters. To further understand the results a main effect plot was generated as well, in order to get an idea of the relation between the response and the selected parameters. The analysis was performed utilizing MINITAB software, a statistical analysis tool. The Pareto chart and the consequently derived main effect plots are presented in Fig. 6. In this study, a significance level of $\alpha=0.1$ had been used as opposed to 0.05 , as with a value of 0.05 no correlation had been found, and since 0.1 is used at early screening stage [23]. It can be noted that on carrying out the analysis taking into account all the parameters, none seems to have a significant influence on the results, with deep drawing height being a major but not sufficiently significant parameter
Fig. 5 Geometrical deviation for pyramid in outwards direction (ID 7): (a) deep-drawn part, (b) reshaped part

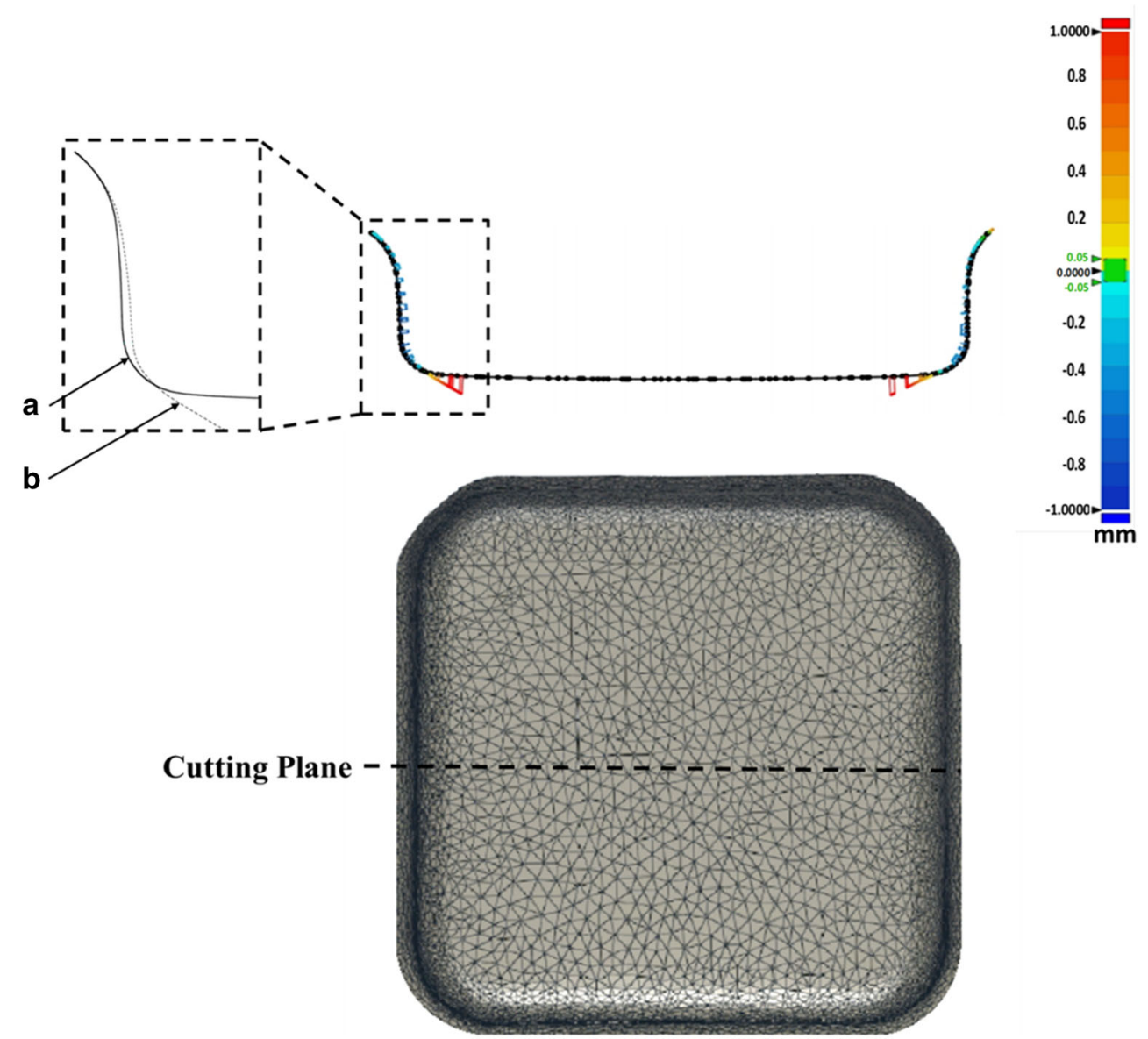


Pareto Chart of the Effects (response is MAX DEV., $\alpha=\mathbf{0 . 1}$ )
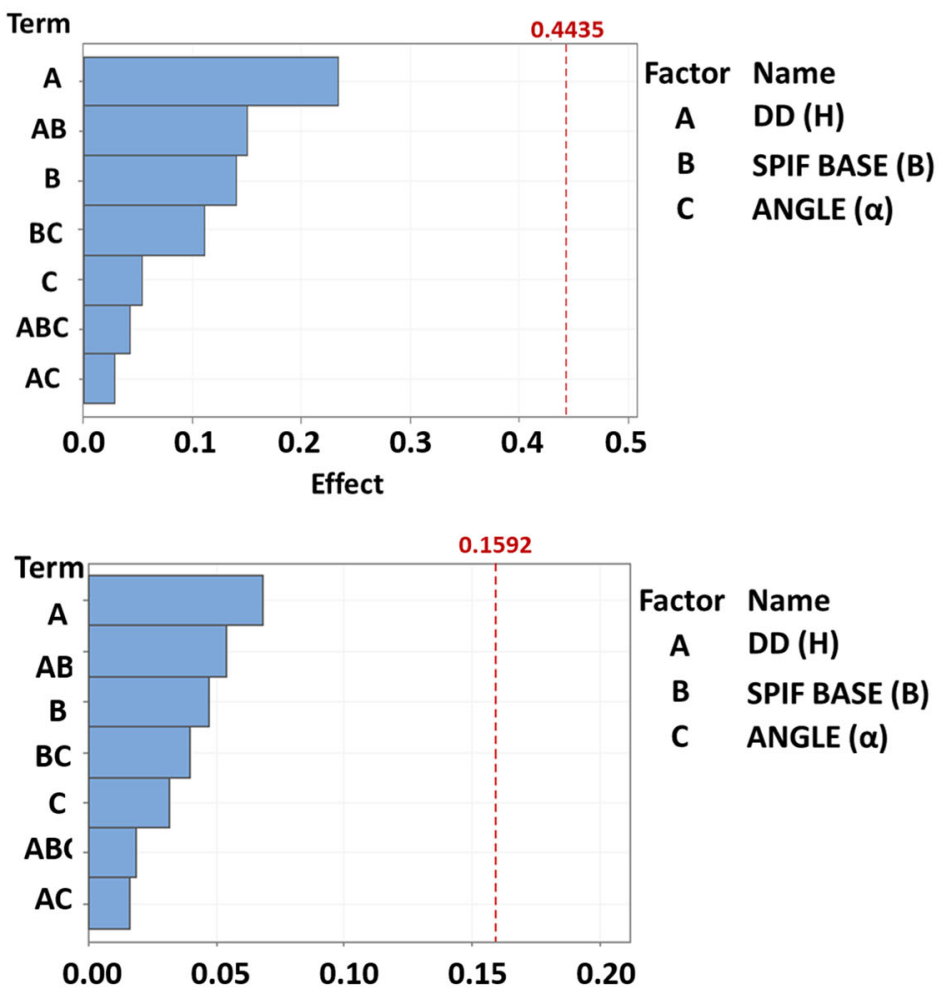

Fig. 6 Pareto chart and main effect plots for pyramid in outwards direction

of the three. Although a certain amount of geometrical deviation was observed, it is still limited.

\subsection{SPIF operation in inward direction}

In order to further study the effects of SPIF process on the part geometry, SPIF operations performed in the inward direction were also performed on the bottom of the DD

\section{Part ID- 14}

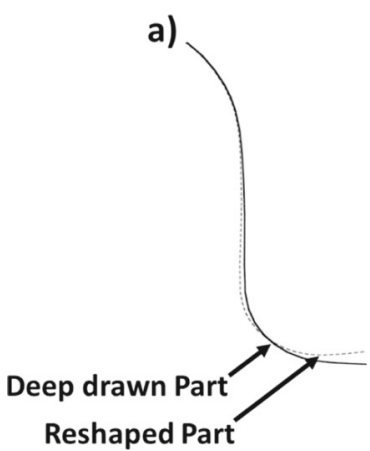

Part ID- 16

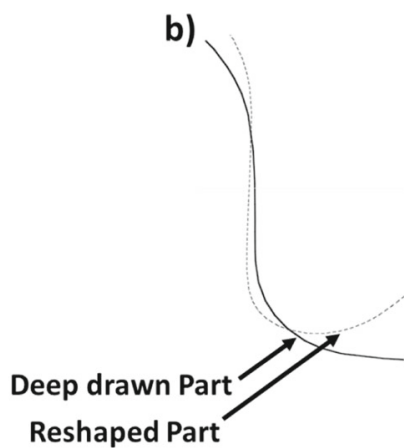

Fig. 7 Geometrical deviation for pyramid in inwards direction for part ID 14 (a) and for part ID 16 (b)
Main Effects Plot for MAX DEV.
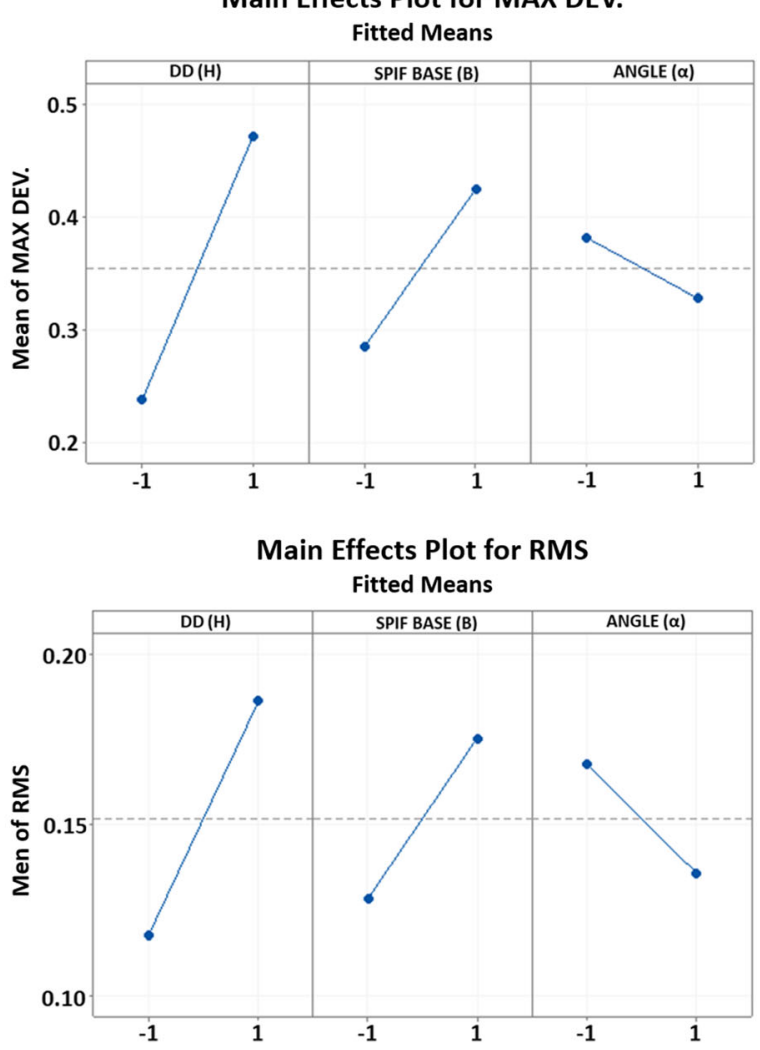

part, and the same number of experiments was carried out as well.

Overall, the geometrical deviation is characterized by a different behavior. Actually, as reported in Fig. 7b, a shortening of the lateral walls while experiencing an outward push, as opposed to the draw in as seen in the first case study. The obtained deviations and the geometric analysis are presented in Table 3. It is possible to see that for IDs 15 and 16 quite high geometrical deviations were observed, in fact the highest values of the entire experimental campaign. These values are characterized by maximum values of SPIF pyramid base (B) and deep drawing height $(\mathrm{H})$. To be more specific, in this case scenario, the maximum geometrical deviation was seen in the case of the experiment ID 15 where the parameters selected were $16 \mathrm{~mm}$ deep drawing height and a pyramid of base $41 \mathrm{~mm}$ at an angle of $30^{\circ}$. Contrary to the results obtained in the first case scenario, the maximum deviation occurs in the most extreme case scenario, indicating an influence of the SPIF base directly at the occurring maximum deviation. The results from the Pareto analysis of the above data are shown in Fig. 8. From the graphs, it can be deduced that two parameters, deep drawing height and the SPIF base, have a significant influence on the result with the SPIF base being a more relevant candidate. This can also be noted from the main effect 
Table 3 Maximum deviations and RMS values recorded and from analysis in inwards direction

\begin{tabular}{llllll}
\hline Experiment ID & $\begin{array}{l}\text { Deep drawing height } \\
(\mathrm{H}, \mathrm{mm})\end{array}$ & $\begin{array}{l}\text { SPIF pyramid base } \\
(\mathrm{B}, \mathrm{mm})\end{array}$ & SPIF pyramid angle $\left(\alpha^{\circ}\right)$ & Maximum deviation (mm) & Root mean squared value \\
\hline 9 & 8 & 34 & $30^{\circ}$ & 0.182 & 0.074 \\
10 & 8 & 34 & $60^{\circ}$ & 0.272 & 0.109 \\
11 & 8 & 41 & $30^{\circ}$ & 0.366 & 0.140 \\
12 & 8 & 41 & $60^{\circ}$ & 0.652 & 0.251 \\
13 & 16 & 34 & $30^{\circ}$ & 0.190 & 0.076 \\
14 & 16 & 34 & $60^{\circ}$ & 0.343 & 0.128 \\
15 & 16 & 41 & $30^{\circ}$ & 1.270 & 0.503 \\
16 & 16 & 41 & $60^{\circ}$ & 1.188 & 0.504 \\
\hline
\end{tabular}

plot which indicates that the occurring geometrical deviations increase with increasing both selected SPIF base and deep drawing height values.

To visualize the effect of SPIF pyramid base on geometric deviation due to reshaping, in Fig. 7 a comparison of geometric deviation of part ID 14 and ID 16 is reported. These IDs differ only in the pyramid base parameter. Actually in the part with higher B value, a higher deviation occurs and this is due to a slight buckling effect occurring in the inward case scenario under specific conditions.

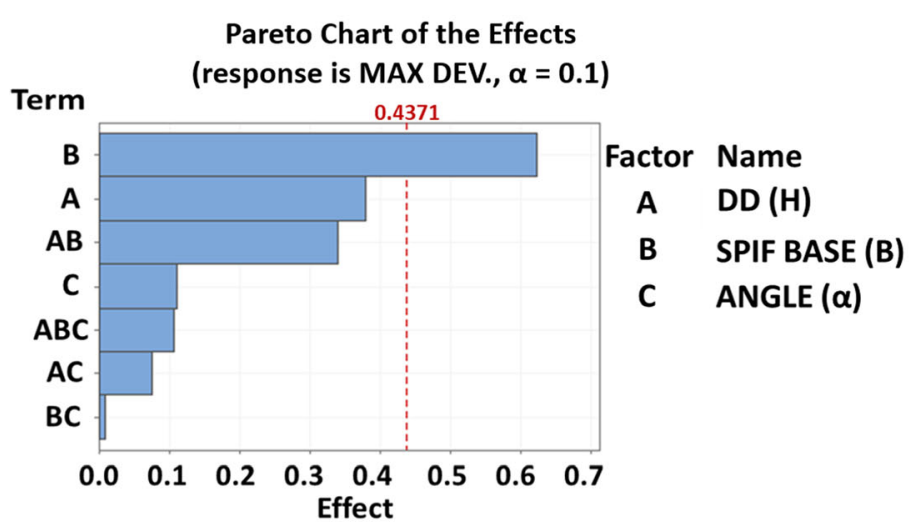

Pareto Chart of the Effects (response is RMS, $\alpha=\mathbf{0 . 1}$ )

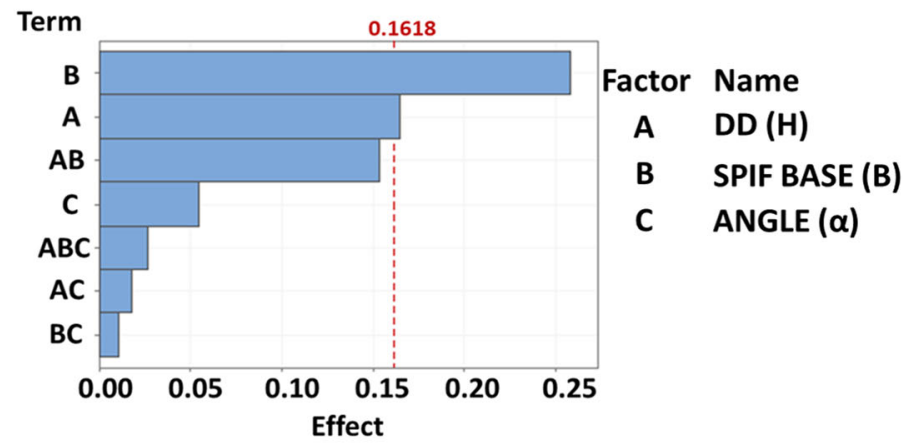

Fig. 8 Pareto chart and main effect plots for pyramid in outwards direction
To provide information on the buckling mechanism, it is necessary to analyze the force occurring during SPIF. Specifically, as reaction to deformation superimposed, tridimensional force is applied on the tool during SPIF. The force trends as well as its analytical formulation have been widely analyzed by researchers [24, 25]. Basically, force trends along three main directions were analyzed in the past and it was observed that during the forming, spire based tool paths yield a stable trend for Fz and two sinusoidal signals for Fx and Fy [24]. The extent of the Fz component is significantly higher

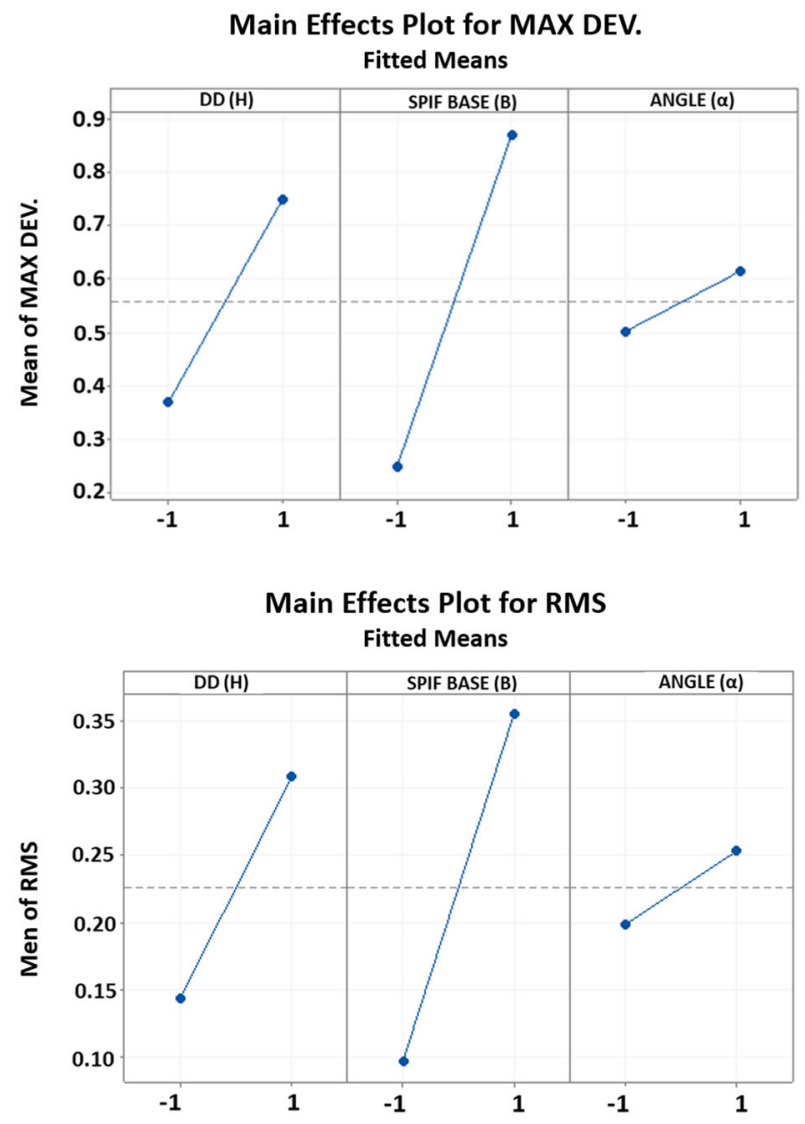

Fig. 8 Pareto chart and main effect plots for pyramid in outwards direction 
than Fx and Fy ones. The force changes with varying material properties and process parameter settings (wall angle, tool diameter, step down) $[24,25]$. In order to better understand the higher buckling effect when B increases, a linear buckling analysis was developed on a simplified model to provide clarity concerning the mechanics perspective. To be more specific, a finite element (FE) model developed using the Structural Analysis Program (SAP2000) was set up, considering 1088 rectangular mesh elements. The simplified deep-drawn part was modeled using shell elements, a sample vertical force equal to $1 \mathrm{kN}$ was applied, and three different analyses, varying the point force location, were launched. The details and the results of the developed analyses are reported in Fig. 9. It is apparent that the closer the point force location is to the vertical walls the higher the buckling effect. Such an effect is shown by analyzing both the stress status and the resulting geometrical deviation (Fig. 9c). For the reshaping case study analyzed in the present paper, the results are consistent with the latter presented analysis. In fact, the larger the pyramid base (the closer the application point of the SPIF force to the vertical walls) the higher the bucking risk/effect as proved by the Pareto analyses previously discussed.

\section{Conclusions}

This paper contributes to lay the ground concerning reshaping process of end-of-life products. In particular, the performance of SPIF process was analyzed as process to enable reshaping of sheet EoL components. Specifically, the geometrical deviation as a consequence of SPIF operations was studied on the non-worked zones of the EoL component. For this aim, two different SPIF directions (named inwards and outwards) were analyzed; the effect of some geometrical parameters was taken into account. The paper, by a wide experimental campaign, revealed two different geometrical deviations as the direction of SPIF changes. In the outward case, limited deviation occurred and basically a draw in of the lateral walls of the EoL part occurred. For this case study, the statistical analyses did not reveal any significant correlation between the variation of geometrical parameters and the geometrical distortion indicators (Maximum deviation and RMS). With regard the inward case study, a different phenomenon was observed. In fact, SPIF reshaping causes a shortening of the lateral walls as well as an outward displacement, actually a limited buckling phenomenon was observed. For the inward approach, higher
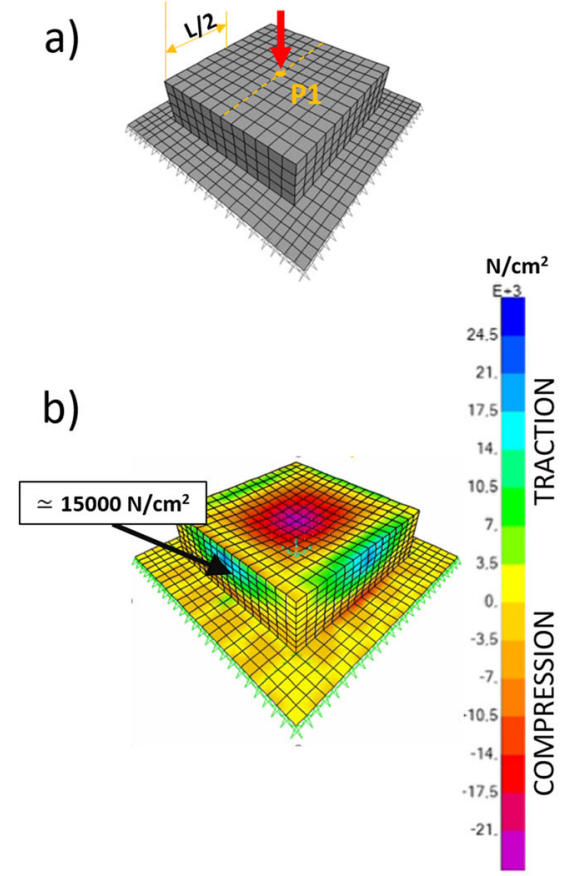

c)

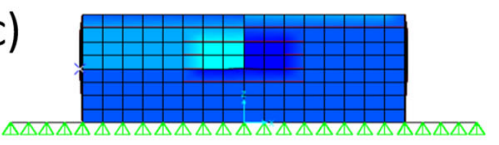

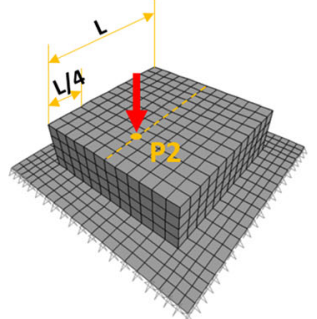
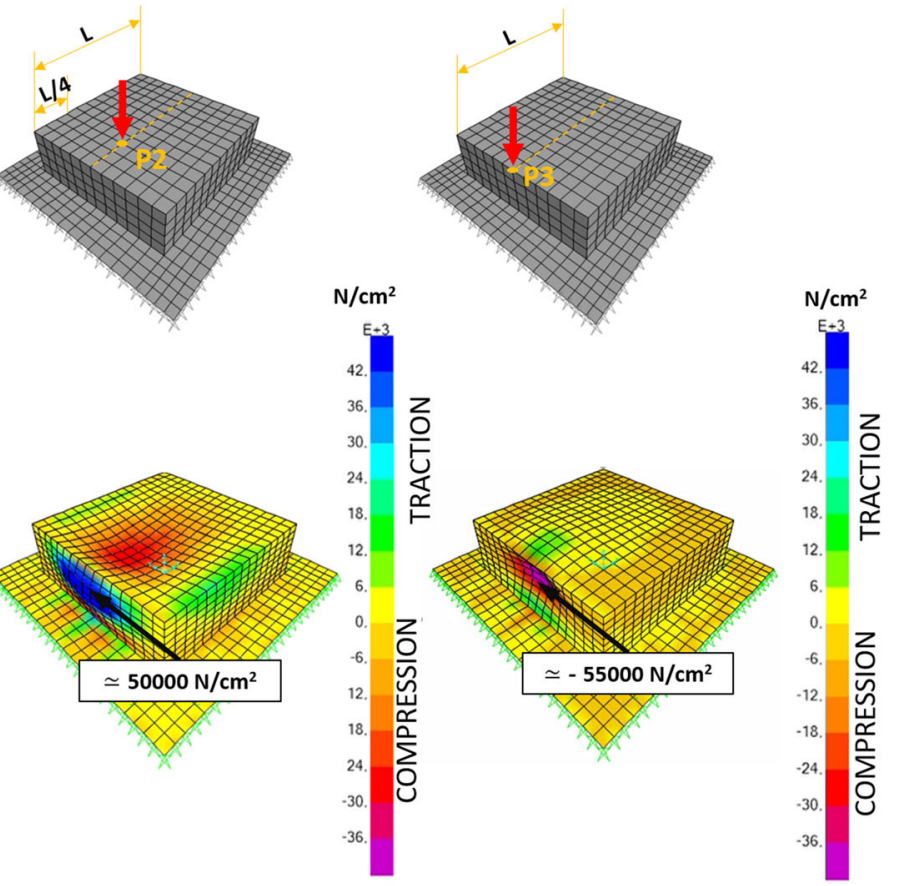

30.
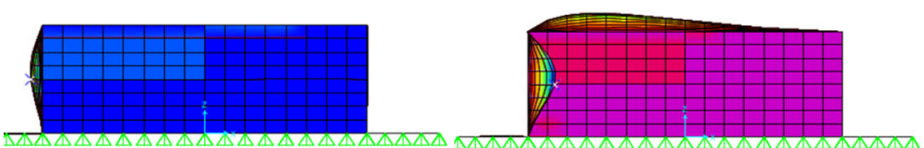

Fig. 9 Buckling linear analysis: a three different point force locations, $\mathbf{b}$ shell stress status, $\mathbf{c}$ simulated geometrical deviation 
geometric deviation occurred, and Pareto chart analyses and main effect plot revealed a correlation between geometrical deviation and SPIF base as well as deep drawing height. Actually, the SPIF base showed a higher influence as if affects both the maximum deviation and the RMS. The deep drawing height slightly affects only the RMS performance. Overall, performances of the SPIF process as reshaper are promising, although this research field deserves to be further explored. The capability of SPIF in changing the shape of EoL components is to be analyzed and structured in design rules. It is worth mentioning that the extent of deformation applicable on an EoL component depends both on the formability performance of the selected processes for reshaping (in the present case SPIF) as well as on the conditions (thickness distributions) of the recovered component. Besides thickness distribution, the overall material condition/properties of the EoL material should be also assessed prior to reshaping. Change in mechanical properties or creep occurrence could compromise the reshaping approach by SPIF. In the present paper, it is assumed that no specific natural precipitation hardening phenomena have occurred during the part life. What is more, it is assumed that no creep phenomena were induced in the material. Such assumption is quite plausible for the considered aluminum alloy as well as for the potential applications of the obtained reshaped component. Nevertheless, in an industrial environment the inspection step becomes crucial for a successful reshaping strategy implementation. Thinning distribution of EoL and material properties/conditions are crucial pieces of information to properly design the reshaping. This pieces of information will allow correct identification of the zones of EoL component to be reshaped. In order to explore the capability of SPIF to actually change the shape, this approach needs an analysis with varying the kind and extent of the first deformation step. Along with deep drawing mechanics, stretching, bending, and more complex strain histories have to be used as processes to get the EoL component. For each case, the performance of SPIF has to be analyzed both in terms of formability and accuracy. Moreover, to fully explore the potential of reshaping, other flexible sheet metal forming processes should be analyzed. Other candidates could be hydroforming (possibly the assisted temperature versions) and hot gas forming. These options deserve to be explored to identify the most suitable process with varying EoL properties. Finally, some innovative fixture to be used during SPIF experiments could be thought of, to prevent distortion in extreme case studies.

Author contribution Omer Zaheer: performing experimental campaign and statistical analysis, draft writing.

Giuseppe Ingarao: conceiving the idea, overall coordination and draft and final paper writing.

Antonina Pirrotta: linear buckling analysis development.

Livan Fratini: overall revision and research coordination.
Funding Open access funding provided by Università degli Studi di Palermo within the CRUI-CARE Agreement.

Data availability (data transparency) Not applicable.

Code availability (software application or custom code) Not applicable.

\section{Declarations}

Conflict of interest (include appropriate disclosures) The authors declare no competing interests.

Open Access This article is licensed under a Creative Commons Attribution 4.0 International License, which permits use, sharing, adaptation, distribution and reproduction in any medium or format, as long as you give appropriate credit to the original author(s) and the source, provide a link to the Creative Commons licence, and indicate if changes were made. The images or other third party material in this article are included in the article's Creative Commons licence, unless indicated otherwise in a credit line to the material. If material is not included in the article's Creative Commons licence and your intended use is not permitted by statutory regulation or exceeds the permitted use, you will need to obtain permission directly from the copyright holder. To view a copy of this licence, visit http://creativecommons.org/licenses/by/4.0/.

\section{References}

1. Worrell E, Allwood J, Gutowski T (2016) The role of material efficiency in environmental stewardship. Annu Rev Environ Resour 41:575-598

2. Olivetti EA, Cullen JM (2019) Toward a sustainable materials system. Science 360(6396):1396-1398

3. Tolio T, Bernard A, Colledani M, Kara S, Seliger G, Duflou JR, Battaia O, Takata S (2017) Design, management and control of demanufacturing and remanufacturing systems. CIRP Ann Manuf Technol 66:585-609

4. Li X, Baffari D, Reynolds AP (2018) Friction stir consolidation of aluminum machining chips. Int J Adv Manuf Technol 94(5-8): 2031-2042

5. Duflou JR, Tekkaya AE, Haase M, Welo T, Vanmeensel K, Kellens K, Dewulf W, Paraskevas D (2015) Environmental assessment of solid state recycling routes for aluminium alloys: can solid state processes significantly reduce the environmental impact of aluminium recycling? CIRP Annals Manuf Technol 64:37-40

6. Baffari D, Reynolds AP, Masnata A, Fratini L, Ingarao G (2019) Friction stir extrusion to recycle aluminum alloys scraps: energy efficiency characterization. J Manuf Process 43:63-69

7. Buffa G, Baffari D, Ingarao G, Fratini L (2020) Uncovering technological and environmental potentials of aluminum alloy scraps recycling through friction stir consolidation. Int J Precision Eng Manuf Green Technol 7(955-964):1-10

8. Cooper DR, Allwood JM (2012) Reusing steel and aluminum components at end of product life. Environ Sci Technol 46:10334 10340

9. Sutherland JW, Adler DP, Haapala KR, Kumar V (2008) A comparison of manufacturing and remanufacturing energy intensities with application to diesel engine production. CIRP Ann Manuf Technol 57:5-8

10. D'Adamo I, Rosa P (2016) Remanufacturing in industry: advices from the field. Int J Adv Manuf Technol 86(9-12):2575-2584 
11. Zhang K, Li D, Gui H, Li Z (2019) An adaptive slicing algorithm for laser cladding remanufacturing of complex components. Int $\mathrm{J}$ Adv Manuf Technol 101(9-12):2873-2887

12. Zhang X, Cui W, Li W, Liou F (2019) Effects of tool path in remanufacturing cylindrical components by laser metal deposition. Int J Adv Manuf Technol 100(5-8):1607-1617

13. Tilwankar AK, Mahindrakar AB, Asolekar SR (2008) Steel recycling resulting from ship dismantling in India: implications for green house gas emissions. Dismantling of obsolete vessels: $1-$ 10

14. Brosius A, Hermes M, Ben Khalif N, Trompeter M, Tekkaya AE (2009) Innovation by forming technology: motivation for research. Int J Mater Form 2:29-38

15. Takano H, Kitazawa K, Goto $\mathrm{T}$ (2008) Incremental forming of nonuniform sheet metal: possibility of cold recycling process of sheet metal waste. Int J Mach Tools Manuf 48:477-482

16. Abu-Farha FK, Khraisheh MK (2008) An integrated approach to the superplastic forming of lightweight alloys: towards sustainable manufacturing. Int J Sustain Manuf 1:18-40

17. Ingarao G, Zaheer O, Campanella D, Fratini L (2020) Re-forming end-of-life components through single point incremental forming. Manuf Lett 24:132-135. https://doi.org/10.1016/j.mfglet.2020.05. 001

18. Ingarao $\mathrm{G}$, Zaheer O, Fratini L (2021) Manufacturing processes as material and energy efficiency strategies enablers: the case of single point incremental forming to reshape end-of-life metal components. CIRP J Manuf Sci Technol 1(32):145-153

19. McAnulty T, Jeswiet J, Doolan M (2017) Formability in single point incremental forming: a comparative analysis of the state of the art. CIRP J Manuf Sci Technol 16:43-54. https://doi.org/10. 1016/j.cirpj.2016.07.003

20. Malhotra R, Xue L, Belytschko T, Cao J (2012) Mechanics of fracture in single point incremental forming. J Mater Process Technol 212:1573-1590

21. Silva MB, Nielsen PS, Bay N, Martins PAF (2011) Failure mechanisms in single-point incremental forming of metals. Int $\mathrm{J}$ Adv Manuf Technol 56(9-12):893-903

22. Li Y, Liu Z, Lu H, Daniel WB, Liu S, Meehan PA (2014) Efficient force prediction for incremental sheet forming and experimental validation. Int J Adv Manuf Technol 73(1-4):571-587

23. Evans M (2009) Minitab manual. W H Freeman

24. Aerens R, Eyckens P, Van Bael A, Duflou J (2010) Force prediction for single point incremental forming deduced from experimental and FEM observations. Int J Adv Manuf Technol 46:969-982

25. Li Y, Daniel WJT, Liu Z, Lu H, Meehan PA (2015) Deformation mechanics and efficient force prediction in single point incremental forming. J Mater Process Technol 221:100-111

Publisher's note Springer Nature remains neutral with regard to jurisdictional claims in published maps and institutional affiliations. 